\title{
Herbal treatment in asthma and COPD - current evidence
}

\author{
Rebecca Clarke ${ }^{1,2^{*}}$, Fionnuala T Lundy ${ }^{1,2}$ and Lorcan McGarvey ${ }^{1,2}$
}

\begin{abstract}
Asthma and COPD are chronic inflammatory respiratory diseases affecting millions of people worldwide and increasing in prevalence. Current treatment options for both conditions aim to alleviate symptoms, improve patient quality of life and prevent disease progression rather than cure the underlying condition itself. Treatments available to patients include anti-inflammatory therapies, bronchodilators and inhaled corticosteroids. While these treatments have been deemed effective at alleviating disease symptoms and exacerbations they are not without their limitations. Overuse of some therapies can induce adverse effects in some patients such as increased risk of developing pneumonia and cardiac co-morbidities. Along with the risks of side effects not all patients will respond to the current treatment options and therefore there is an unmet need for additional or alternative treatments for asthma and COPD. One such area showing good promise in providing an alternative or add-on therapy is that of phytomedicine. Phytomedicine is defined as a plant-based traditional medical practice that uses various plant materials in modalities considered both preventive and therapeutic. This review focuses on recent human clinical trials using plant-based medicines for the treatment of asthma and COPD.
\end{abstract}

Keywords: Asthma; COPD; Phytomedicine; Plant-based medicine

\section{Introduction}

Asthma and chronic obstructive pulmonary disease (COPD) are common inflammatory obstructive lung diseases which affect many millions of people worldwide [1-3]. While advances in basic and clinical research have led to important advances in drug therapy and improvements in care, both conditions are increasing in prevalence and are associated with considerable morbidity and mortality. Although mortality rates for asthma are relatively low, representing only $1 \%$ of all deaths [4], it is recognised that in many cases that death could have been avoided with better routine care; COPD, however, is the $4^{\text {th }}$ leading cause of death [3] and is projected to rise to the second most common cause of death worldwide by 2020. Both conditions cause a significant impairment in quality of life due to impacts on patients' physical and psychological well-being. In addition, the social and economic effects are striking; among the most

\footnotetext{
* Correspondence: rclarke313@qub.ac.uk

${ }^{1}$ Centre for Immunity \& Infection, School of Medicine, Dentistry and

Biomedical Sciences, Queen's University, Belfast, UK

${ }^{2}$ Centre for Infection and Immunity, School of Medicine, Dentistry and

Biomedical Sciences, Health Sciences Building, 97 Lisburn Road, Belfast BT9
} $7 A E, U K$

\section{Springer}

(c) 2015 Clarke et al. This is an Open Access article distributed under the terms of the Creative Commons Attribution License (http://creativecommons.org/licenses/by/4.0), which permits unrestricted use, distribution, and reproduction in any medium, provided the original work is properly credited. important are the escalating costs associated with unscheduled medical care, hospitalisations and loss of productivity. Oral and inhaled anti-inflammatory and bronchodilator medications have formed the basis of treatment recommendations for both conditions $[5,6]$ for the last three decades and despite proven efficacy there is a recognition that therapeutic options are limited and not without adverse effects. Thus there is a need to consider other therapeutic options including phytomedicines which could be used to complement existing treatments. In this article we have undertaken a review of the existing literature of the NCBI PubMed database, which provides access to the MEDLINE and NLM databases, using the search terms herbal/plant/ phytomedicine and asthma/COPD. Results were then filtered to only include human clinical trials within the last 10 years.

\section{Current treatments}

Asthma is a chronic inflammatory airway disease arising from a complex interaction between the immune system and resident cells of the lung to induce the cardinal features of bronchial hyper-responsiveness, increased 
mucus production, narrowing of the airways and airway remodelling. A detailed review of the pathophysiology of asthma has been covered extensively elsewhere and is outside the scope of our article $[1,7,8]$. The most important clinical consequences of this inflammatory process are the exacerbations of disease causing airway narrowing and debilitating bouts of shortness of breath, wheezing, chest tightness and cough. Most asthma treatments aim to control these symptoms and reduce the frequency of exacerbations and current recommendations advocate the use of anti-inflammatory treatments, in particular inhaled corticosteroids (ICS) and bronchodilators such as short and long acting $\beta_{2}$-adrenergic agonists (LABA; 5). However, there is concern around the inappropriate use of asthma medications, in particular the overuse of inhaled corticosteroids in children, which can effect bone growth, and the inappropriate use of long acting bronchodilator therapy in isolation which has been associated with increased morbidity [9]. As well as the risk of these possible adverse effects not all patients respond to these treatments and non-adherence to treatment is common due to issues such as complex treatment regimens, poor inhalation technique and delayed results [10] thus there is an unmet medical need for complementary therapies for asthma.

COPD presents with similar symptoms to asthma such as persistent cough, wheezing and shortness of breath and is caused by an exaggerated inflammatory response to noxious particles and gases (reviewed in $[2,11])$. Cigarette smoke is the leading cause of COPD in the developed world [12], while indoor air pollution due to the burning of biomass fuels is the biggest risk factor in the developing world [13]. The inflammatory response induced by these noxious stimulants can result in emphysema and airway destruction caused by factors such as imbalances between proteinases and anti-proteinases resulting in increased proteolytic activity, and oxidants and antioxidants which leads to increased oxidative stress $[14,15]$. Treatment for COPD include cessation of cigarette smoking which in some cases can stop or slow disease progression, bronchodilators and inhaled corticosteroids. As in asthma, these therapies are used to treat the symptoms and control the disease rather than cure the underlying condition. There is considerable evidence that inhaled corticosteroids and bronchodilators improve lung function and quality of life and reduce disease exacerbations $[16,17]$. While such treatments are endorsed in international treatment guidelines [6] only a small population of COPD patients show significant improvements and concerns have emerged regarding the use of inhaled steroids and higher rates of pneumonia and the safety of bronchodilator therapy in COPD patients with cardiac co-morbidities. Therefore more effective and safe treatments for COPD remain an important therapeutic objective.

\section{Review \\ A review of phytomedicine in the treatment of asthma and COPD}

Phytomedicine is defined as a plant-based traditional medical practice that uses various plant materials in modalities considered both preventive and therapeutic. Herbs and plants naturally contain many active chemicals and thus drugs derived from such sources can have multiple health benefits when administered to patients. Due to the presence of multiple active compounds in phytomedicines they are an ideal candidate for treating conditions with a variety of symptoms such as inflammatory diseases which affect multiple systems.

Historically, particularly in Chinese and other Asian cultures, plant-based medicines have been used to treat and prevent lung disease, and to this day remain a major therapeutic option; thus the idea of using plant-derived medicines for treatment of asthma and COPD is not a new concept. In fact some commonly used conventional drugs are derived from plant and herbal extracts. Atropine, a naturally occurring alkaloid extracted from Atropa belladonna, acts on the parasympathetic nervous system and has an antimuscarinic effect which inhibits the contraction of smooth muscle tissue and reduces mucus secretion. However, despite the anti-mucus secreting properties and smooth muscle relaxant effect, atropine was found to be ineffective in improving the symptoms of asthma in clinical trials [18]. Atropine remains a mainstay of treatment of cardiac bradyarrhythmias, and has been used successfully in the treatment of conditions such as amblyopia, also known as lazy eye [19]. While atropine itself was ineffective in treating asthma in clinical trials a derivative of its active compound has been adapted into the anticholinergic drug ipratropium bromide which is used to treat bronchospasm which occurs during COPD and asthma $[6,5]$.

Over the years there has been considerable effort undertaken to explore the efficacy and safety of plantbased medicines and to elucidate the mechanisms through which they might exert a therapeutic effect. In the area of asthma and COPD therapies many promising plant-based treatments have arisen from these studies. A summarised version of the search results can be found in Additional file 1: Table S1 and Table S2 for asthma and COPD respectively. A summary of the compounds mentioned and their beneficial effect can be found in Additional file 1: Table S3.

For the purpose of this review we have selected a number of these studies for further discussion to 
illustrate the potential of plant-based medicines for use in the treatment and management of asthma and COPD.

\section{Plant-derived therapies for asthma}

A number of plant-based medicines have shown promising results in clinical studies of asthma such as Anti-asthma Herbal Medicine Intervention (ASHMI). ASHMI is a combination of 3 extracts; Ling Zhi from Ganoderma lucidem, $\mathrm{Ku}$ Shen from Sophora flavescentis and Gan Cao from Glycyrhhiza uralensis, which has shown potential for the treatment of asthma in both in vitro and in vivo (subsections $i$ ) and ii) below respectively) models as well as in human patients. In vivo studies carried out by Zhang et al. [20] in $\mathrm{BALB} / \mathrm{c}$ mice sensitised with ovalbumin (OVA) and alum showed that ASHMI abolished the early-phase airway responses and prevented the late-phase airway hyperresponsiveness. Their findings also suggested that ASHMI directly affected airway narrowing through inhibition of acetylcholine-induced tracheal ring constriction ex vivo and increased production of the smooth muscle relaxants prostacyclin and prostaglandin I 2 (PGI2). ASHMI has also been shown to reduce lung inflammation and mucus in an aged mouse model of late-onset asthma [21].

i) Preclinical ASHMI studies: In vitro studies using a human lung fibroblast cell line showed that Gan Cao, one of the extracts used in ASHMI, decreased secretion of interleukin (IL) 8, eotaxin 1 and stat 6 $[22,23]$ demonstrating the anti-inflammatory property of this extract and a possible mechanism of action in the treatment of asthma, particularly the recently described subtype 'neutrophilic asthma' where severe asthma patients suffer from airway neutrophilia (reviewed in [24]). Other in vitro studies carried out in primary mouse cells demonstrated a decrease in tumour necrosis factor alpha $(\mathrm{TNF} \alpha)$, nuclear factor kappa $\beta\left(\mathrm{NF}_{\kappa} \mathrm{B}\right)$ and brain derived neurotrophic factor (BDNF) levels in cells pretreated with ASHMI in response to lipopolysaccharide (LPS) [25], again emphasising the anti-inflammatory properties of this plant-based medicine.

ii) Clinical ASHMI studies: Clinical trials of ASHMI have been undertaken in a 4-week double-blind, randomised, trial carried out by Wen et al. [26] comparing the effects of oral ASHMI, 4 capsules ( $0.3 \mathrm{~g} /$ capsule) 3 times daily, with that of oral prednisone, $20 \mathrm{mg}$ once daily, in patients with moderate to severe persistent asthma over a period of 4 weeks. Both ASHMI and prednisone significantly reduced symptoms and improved lung function from baseline with prednisone group showing significantly greater improvements in lung function than the ASHMI group. Both compounds exerted anti-inflammatory effects and no adverse effects were reported during the short treatment duration. While ASHMI displayed significantly less improvements in lung function when compared to prednisone it stilled displayed clinically relevant reductions in patient symptom scores and enhancements in lung function. Therefore ASHMI can be considered a possible alternative therapy for patients suffering with less severe asthma as, unlike prednisone, there have been no documented adverse side effects reported during ASHMI therapy.

Another plant-based medicine used for the treatment of asthma is Aleurites moluccana, a native tree of Indonesia and India which has been used in traditional remedies not only for the treatment of asthma but for pain, fever and headaches [27-29]. More recently, the anti-nociceptive effects of $A$. molluccana $[30,31]$ and its mechanical anti-hypersensitivity properties [32] have been investigated. A. mollucanna has also been found to possess antiviral [33] and antimicrobial properties [34] demonstrating how the presence of multiple active compounds in plant extracts can have several benefits to patients. Due to this historical link between A. mullucanna and anti-nociceptive and antiinflammatory therapies, A. mullucanna extracts have been used to produce analgesic and anti-inflammatory phytomedicines $[35,36]$. The major focus of this work was on the wound healing effects of A. mollucanna extracts, although the use of this plant in traditional remedies for asthma suggests that there is a possibility for the active compounds of A. mullucanna to be adapted to produce a phytomedicine for asthma and its related symptoms.

Nigella sativa, a plant native to South East Asia is known for its relaxant effect on smooth muscle tissue [37-39]. In addition, Boskabady and colleagues have demonstrated that extracts and oils from $N$. sativa have inhibitory effects on histamine (H1) receptors [40], stimulatory effects on $\beta$-adrenergic receptors [41] and anti-tussive effects [42]. To translate these promising in vitro findings Boskabady and colleagues set out to investigate the effect of boiled $N$. sativa extract on lung function in asthmatic patients [43]. In this study they compared the bronchodilatory effects of $N$. sativa with those of theophylline in 15 asthmatics. They found that $N$. sativa did induce bronchodilation within $30 \mathrm{~min}$ of administration but the magnitude was significantly less than observed with theophylline and that both agents were significantly less effective than the beta- 2 agonist salbutamol. Nonetheless they concluded that $N$. sativa has relatively potent bronchodilatory effects but when 
given orally it is less effective than conventional bronchodilators. It is possible that the bronchodilatory effects of compounds such as $N$. sativa could be enhanced if formulated as inhaled therapy with delivery of the active compounds directly to the airway.

\section{Plant-based therapies for COPD}

As mentioned above, COPD is characterised by airflow obstruction that is fixed or only partially reversible and which declines progressively over time. Treatments consist of inhaled bronchodilators and corticosteroids either as monotherapy or in combination and aim to decrease symptom severity and improve QOL [6]. For some patients, treatment with roflumilast a phosphodiesertase-4 inhibitor has been shown to be effective although not without adverse effects such as weight loss and nausea [44]. Patients with COPD commonly have important comorbidities in particular cardiovascular, metabolic and renal impairment. Therefore the safety profile of current and novel therapies must be carefully scrutinised. Perhaps of most interest recently has been the concern regarding the safety of inhaled corticosteroids especially at high doses, with an increased rate of pneumonia having been reported in a number of large clinical trials in patients with moderate to severe COPD who received corticosteroid-containing inhaled therapy $[16,45,46]$. One approach to overcome this problem would be to identify biomarkers to help identify those patients most likely to benefit from inhaled corticosteroids and least likely to suffer adverse effects. The discovery of novel safe and effective therapies for COPD including those derived from plant-based medicines represents an alternative and attractive solution. The following section reviews some of the clinical trials of plant-based medicine undertaken in the last 10 years in COPD patients. Details of these trials have been summarised in Additional file 1: Table S2. Reducing disease exacerbations and improving quality of life (QOL) represent important treatment goals in the management of COPD. A number of clinical trials of herbal and plant-based treatments for COPD have focused on these important treatment outcomes. Li et al. [47] investigated the effect in an open label study of the combination of three different traditional Chinese plant-based medicines, $\mathrm{Bu}-\mathrm{Fee}$ Jian-Pi, Bu-Fei Yi-Shen and Yi-Qi Zi-Shen, formulated as granules and given as add-on therapies to conventional Western medicine on symptoms and QOL in COPD patients. They found that compared to conventional therapy the addition of the plant-based medicine combination was associated with improved symptom scores (cough, sputum, chest tightness, and breathlessness) and improvement in QOL scores across the physical, psychological, environmental and social domains.
A number of clinical trials have investigated the effect of plant-based medicine on lung function and their potential anti-inflammatory effect on systemic circulation. Liu et al. [48] studied the effects of the Yiqibushenhuoxue, a complex mixture of herbs used in traditional Chinese medicine believed to relieve respiratory symptoms such as cough and shortness of breath as well as improve kidney and splenic function, as a complementary therapy for COPD. The study was designed as a 12-week open label comparison of the plant-based mixture and a fixed dose combination ICS/LABA therapy compared to the ICS/ LABA alone in patients with stable COPD. Study endpoints were QOL measured using the St George's Respiratory Questionnaire (SGRQ) and lung function (\% predicted $\mathrm{FEV}_{1}$ and $\mathrm{FEV}_{1} / \mathrm{FVC}$ ). When compared to those in the control group, participants allocated to the plant-based treatment group had similar improvements in lung function but reported significantly greater improvements in SGRQ scores. Based on these findings, the authors proposed larger and longer studies to determine the optimal effect of Yiqibushenhuoxue in patients with COPD. Whilst this particular study reported no improvements in lung function when the plant-based medicine was added to conventional COPD treatment other researchers have seen marked improvement in lung function following the use of a plant-based medicine. Guo et al. [49] conducted a randomised, double-blinded, placebo-controlled study investigating the effects of $\mathrm{Bu}$-Fei granules on the frequency of COPD exacerbations along with lung function and serum inflammatory mediator levels. BuFei granules have been historically used in traditional Chinese medicine to enhance lung immune functions. In this study patients were not permitted to use any other form of COPD medication whilst receiving Bu-Fei granules. The authors observed a significant reduction in symptom scores in the treatment group when compared to the control group and they also saw an improvement in $\mathrm{FEV}_{1}, \mathrm{FVC}, \mathrm{FEV} / \mathrm{FVC}$ and PEF in the treatment group which did not occur in the patients receiving placebo. When inflammatory mediator levels were measured they found that the levels of IL8, TNF $\alpha$ and transforming growth factor beta (TGF $\beta$ ) were all reduced in patient serum samples from the treatment group with no major changes occurring in those of the control group. These results show that $\mathrm{Bu}-\mathrm{Fei}$ granules alleviate the symptoms of COPD, may help delay the deterioration of lung function in patients and also have an anti-inflammatory effect. In this study they also carried out a follow up examination 6 and 12 months after the trial ended and found that the patients of the treatment group experienced significantly fewer exacerbations than the 
patients of the control group suggesting that $\mathrm{Bu}$-Fei granules may have a long-lasting benefit over conventional medication.

\section{Conclusion}

The current approach to managing both asthma and COPD is predominately based on the use of inhaled bronchodilators and corticosteroids. For a large number of patients these treatments are effective at improving lung function and quality of life and reducing symptoms and disease exacerbations. However, concerns exist regarding the adverse effects of these treatments in some patients especially when used in high dose. Furthermore there is growing recognition of subgroups of patients that appear refractory to current therapy and who are considered 'difficult to treat'. At present, novel and expensive biologic therapies are being developed to address this unmet need. Alternative approaches to address the issue of adverse effects and reduced efficacy include the use of phytomedicines. However progress in this area is hampered by a lack of compelling evidence. Therefore there is a need for properly conducted scientific research into the effects of safe, plant-based medicines in asthma and COPD. Of the articles included in this review the vast majority were carried out as randomised, double-blind, placebocontrolled trials which shows that an increasing number of research groups are beginning to consider plant-based medicines as serious therapies for diseases rather than as homeopathic or holistic remedies, which has been the traditional opinion of most of the modern world. Along with this change in attitude, these studies have generally yielded positive results in patients following the addition of a plant-based therapy which emphasises the possibility of developing medical treatments for inflammatory diseases which are both efficacious and have minimal adverse side effects as most clinical trials mentioned here did not report any side effects following the use of plant-based medicines. If any side effects were observed they were generally mild and were spontaneously rectified i.e. no further medical interventions were needed [50]. Whilst the majority of the publications mentioned here.

Along with studying the clinical efficacy of these natural compounds it is also important for us to understand the mechanisms through which these compounds exert their effect. While the mechanisms of some promising phytomedicines, such as ASHMI, have begun to be elucidated (reviewed in [51]) the mechanisms of most plant-based medicines remain unknown. There is an increasing willingness within the scientific and medical community to explore the role of phytomedicines for the treatment and management of asthma and COPD. It is, however, important that research and drug development in this area is conducted with integrity and with the same rigorous standards of safety and efficacy as mandated for the development of any novel "conventional" therapy.

\section{Additional file}

\begin{abstract}
Additional file 1: Table S1. A summary of some of the human clinical trials published in the last 10 years fitting the search terms herbal/ plant/phytomedicine and asthma in the NCBI database [26, 50, 52-65]. Table S2. A summary of some of the human clinical trials published in the last 10 years fitting the search terms herbal/plant/phytomedicine and COPD in the NCBI database [47-49, 66-76]. Table S3. A summary of the herbal compounds mentioned in some of the human clinical trials published in the last 10 years and their beneficial effects in patients with asthma and COPD.
\end{abstract}

\section{Abbreviations}

ASHMI: Anti-asthma herbal medicine intervention; BDNF: Brain derived neurotrophic factor; COPD: Chronic obstructive pulmonary disease; FEV: Forced expiratory flow; FVC: Forced vital capacity; H1: Histamine 1; ICS: Inhaled corticosteroids; IL: Interleukin; LABA: Long acting beta 2 adrenergic agonists; LPS: Lipopolysaccharide; NFKB: Nuclear factor kappa beta; OVA: Ovalbumin; PEF: Peak expiratory flow; PGI2: Prostaglandin 12; QOL: Quality of life; SGRQ: St George's respiratory questionnaire;

TGF $\beta$ : Transforming growth factor beta; TNFa: Tumour necrosis factor alpha.

\section{Competing interests}

FTL, LMcG and RC have no competing interests. RC was funded by Bionorica Global Research Initiative.

\section{Authors' contributions}

RC carried out the literature search and drafted the manuscript. FTL and LMCG helped to draft and edit the manuscript. All authors read and approved the final manuscript.

Received: 24 March 2015 Accepted: 15 May 2015

Published online: 08 August 2015

\section{References}

1. Lambrecht BN, Hammad H. The immunology of asthma. Nat Immunol. 2014;16:45-56.

2. Brusselle GG, Joos GF, Bracke KR. New insights into the immunology of chronic obstructive pulmonary disease. Lancet. 2011;378:1015-26.

3. Lopez AD, Mathers CD, Ezzati M, Jamison DT, Murray CJL. Measuring the global burden of disease and risk factors. 2006. p. 1999-2001.

4. Global Asthma Network. http://www.globalasthmanetwork.org.

5. GINA. The Global Initiative for Asthma. 2014. http://www.ginasthma.org.

6. GOLD. Global Strategy for Diagnosis, Management, and Prevention of Chronic Obstructive Pulmonary Disease (GOLD) (Executive Summary). 2014 www.goldcopd.org/Guidelines/guideline-global-strategy-for-diagnosis\%2cmanagement\%2c-and-prevention-of-copd-\%282008-edition\%29.

7. McClafferty H. An overview of integrative therapies in asthma treatment. Curr Allergy Asthma Rep. 2012;14:464.

8. Scichilone N, Benfante A, Morandi L, Bellini F, Papi A. Impact of extrafine formulations of inhaled corticosteroids/long-acting beta-2 agonist combinations on patient related outcomes in asthma and COPD. Patient Relat Outcome Meas. 2014;5:153-62.

9. FDA Drug Safety Communication. Drug labels now contain updated recommendations on the appropriate use of long-acting inhaled asthma medications called Long-Acting Beta-Agonists (LABAs). 2011. http://www.fda.gov/Drugs/DrugSafety/ucm251512.

10. Bender BG. Overcoming barriers to nonadherence in asthma treatment. J Allergy Clin Immunol. 2002;109:S554-9.

11. Roisin RR, Vestbro J. Global initiative for chronic obstructive lung disease. GOLD. 2011. p. 1-74. www.goldcopd.org

12. Pauwels R, Rabe K. Burden and clinical features of chronic obstructive pulmonary disease (COPD). Lancet. 2004;364:613-20. 
13. Salvi SS, Barnes PJ. Chronic obstructive pulmonary disease in non-smokers. Lancet. 2009;374:733-43.

14. Laurell CB. The electrophoretic alpha-1 globulin pattern of serum in alpha-1 antitrypsin deficiency. Scand J Clin Lab Invest. 1963;15:132-40.

15. Rahman I, Adcock IM. Oxidative stress and redox regulation of lung inflammation in COPD. Eur Respir J. 2006;28:219-42.

16. TORCH study group. The TORCH (TOwards a Revolution in COPD Health) survival study protocol. Eur Respir J. 2004;24:206-10.

17. Corhay JL, Louis R. The UPLIFT study (Understanding Potential Long-term Impacts on Function with Tiotropium). Rev Med Liege. 2009;64:52-7.

18. Diaz JE, Dubin R, Gaeta TJ, Pelczar P, Bradley K. Efficacy of atropine sulfate in combination with albuterol in the treatment for acute asthma. Acad Emerg Med. 1997:4:107-13

19. Pediatric Eye Disease Investigator Group. Treatment of severe amblyopia with weekend atropine: results from two randomised clinical trials. J AAPOS. 2009;13:258-63.

20. Zhang T, Srivastava K, Wen MC, Yang N, Cao J, Busse P, et al. Pharmacology and immunological actions of a herbal medicine ASHMI on allergic asthma. Phytother Res. 2010;24:1047-55.

21. Busse PJ, Schofield B, Birmingham N, Yang N, Wen MC, Zhang T, et al. The traditional Chinese herbal formula ASHMI inhibits allergic lung inflammation in antigen-sensitized and antigen-challenged aged mice. Ann Allergy Asthma Immunol. 2010;104:236-46.

22. Matsui S, Matsumoto H, Sonoda Y, Ando K, Aizu-Yokota E, Sato T, et al. Glycyrrhizin and related compounds down-regulate production of inflammatory chemokines IL-8 and eotaxin 1 in a human lung fibroblast cell line. Int Immunopharmacol. 2004;4:1633-44.

23. Matsui S, Sonoda Y, Sekiya T, Aizu-Yokota E, Kasahara T. Glycyrrhizin derivative inhibits eotaxin 1 production via STAT6 in human lung fibroblasts. Int Immunopharmacol. 2006;6:369-75.

24. Nair P, Aziz-Ur-Rehman A, Radford K. Therapeutic implications of 'neutrophilic asthma'. Curr Opin Pulm Med. 2015:21:33-8.

25. Li XM. Treatment of asthma and food allergy with herbal interventions from traditional Chinese medicine. Mount Sinai J Med. 2011;78:697-716.

26. Wen MC, Wei CH, Hu ZQ, Srivastava K, Ko J, Xi ST, et al. Efficacy and tolerability of anti-asthma herbal medicine intervention in adult patients with moderate-severe allergic asthma. J Allergy Clin Immunol. 2005;116:517-24.

27. Leonard DB. Medicine at your feet. Plants and food. 2004. http://www.medicineatyourfeet.com.

28. Elevitch CR, Manner HI. Traditional Tree Initiative-Species Profiles for Pacific Island Agroforestry. 2006. p. 1-16.

29. Duke JA. Handbook of medicinal herbs. USA: CRC Press; 1991.

30. Meyre-Silva C, Mora TC, Santos ARS, Dal Magro J, Yunes RA, Cechinel-Filho V. Preliminary phytochemical and pharmacological studies of Aleurites moluccana leaves [L.] Willd. Phytomedicine. 1998;5:109-13.

31. Meyre-Silva C, Yunes RA, Santos ARS, Dal Magro J, Delle-Monache F, Cechinel-Filho V. Isolation of a C-glycoside flavonoid with antinociceptive action from Aleurites moluccana leaves. Planta Med. 1999;65:293-4.

32. Quintao NML, Meyre-Silva C, Silva GF, Antonialli CS, Rocha LW, LucindaSilva RM, et al. Aleurites moluccana (L.) Willd. leaves: mechanical antinociceptive properties of a standardized dried extract and its chemical markers. Evid Based Complement Altern Med. 2011. p. 1155-65.

33. Locher CP, Witvrouw M, De Bethune M, Burch MT, Mower HF, Davis $H$, et al. Antiviral activity of hawaiian medicinal plants against human immunodeficiency virus type-1 (HIV-1). Phytomedicine. 1996;2:259-64.

34. Locher CP, Burch MT, Mower HF, Berestecky J, Davis H, Van Poel B, et al. Anti-microbial activity and anticomplement activity of extracts obtained from selected hawaiian medicinal plants. J Ethnopharmacol. 1995;49:23-32.

35. Cechinel-Filho V, Bresolin TMB, Bittencourt CMS, Sousa MM, Lucinda-Silva RM, Quintao NLM, et al. Patent PI 0804525-9A2. Rio de Janeiro: INPI; 2007.

36. Cesca TG, Faqueti LG, Rocha LW, Meira NA, Meyre-Silva C, de Souza MM, et al. Antinociceptive, anti-inflammatory and wound healing features in animal models treated with a semisolid herbalmedicine based on Aleurites mullucanna L. Willd. Euforbiaceae standardised leaf extract. J Ethnopharmacol. 2012;143:355-62.

37. Agel MB. The relaxing effect of volatile oil of Nigella sativa seed on vascular smooth muscle. Jordan Ser. 1992;B1:91-100.

38. Aqel MB. Effects of Nigella sativa seeds on intestinal smooth muscle. Intern J Pharmacogn. 1993;31:55-60.
39. Reiter M, Brandt W. Arzneim Forsch Drug Res. Relaxant effects on tracheal and ileal smooth muscles of the guinea-pig. Pharmacotherapy. 1985;35:408-14.

40. Boskabady MH, Shiravi N. Inhibitory effect of Nigella sativa on histamine $(\mathrm{H} 1)$ receptors of isolated guinea pig tracheal chains. Pharmac Biol. 2002;40:596-602.

41. Boskabady MH, Kiani S, Jandaghi P. Stimulatory effect of Nigella sativa on B2-adronceptors of guinea pig tracheal chains. Med J Islam Rep Iran. 2004;18:153-8

42. Boskabady MH, Kiani S, Jandaghi P, Ziaei T, Zarei A. Antitussive of Nigella sativa. Pak J Med Sci. 2004;20:224-8.

43. Boskabady MH, Mohsenpoor N, Takaloo L. Antiasthmatic effect of Nigella sativa in airways of asthmatic patients. Phytomedicine. 2010;17:707-13.

44. Fabbri LM, Calverley PM, Izquierdo-Alonso JL, Bundschuh DS, Brose M, Martinez FJ, et al. Roflumilast in moderate-to-severe chronic obstructive pulmonary disease treated with longacting bronchodilators: Two randomised clinical trials. Lancet. 2009;374:695-703.

45. Calverley PM, Anderson JA, Celli B, Ferguson GT, Jenkins C, Jones PW, et al. Salmeterol and fluticasone propionate and survival in chronic obstructive pulmonary disease. N Engl J Med. 2007;356:775-89.

46. Crim C, Dransfield MT, Bourbeau J, Jones PW, Hanania NA, Mahler DA, et al. Pneumonia risk with inhaled Fluticasone Furoate and Vilanterol compared with Vilanterol alone in patients with COPD. Ann Am Thorac Soc. 2015;12:27-34

47. Li JS, Li SY, Xie Y, Yu XQ, Wang MH, Sun ZK, et al. The effective evaluation on symptoms and quality of life of chronic obstructive pulmonary disease patients treated by comprehensive therapy based on traditional Chinese medicine patterns. Complement Ther Med. 2013;21:595-602.

48. Liu J, Gao F, Li Z. Effect of yiqibushenhuoxue decoction on chronic obstructive pulmonary disease measured by St. George's respiratory disease questionnaire scores and forced expiratory volume. J Tradit Chin Med. 2014;34:445-9.

49. Guo S, Sun Z, Liu E, Feng J, Fu M, Li Y, et al. Effect of bufei granule on stable chronic obstructive pulmonary disease: a randomized, double-blinded, placebo controlled, and multicenter clinical study. J Tradit Chin Med. 2014;34:437-44.

50. Park CS, Kim TB, Lee JY, Park JY, Jeong SS, Lee YD, et al. Effects of add-on therapy with NDC-052, an extract from Magnoliae Flos, in adult asthmatic patients receiving inhaled corticosteroids. Korean J Intern Med. 2012;27:84-90.

51. Li XM, Brown L. Efficacy and mechanisms of action of traditional Chinese medicines for treating asthma and allergy. J Allergy Immunol. 2009;123:297-306.

52. Wong EL, Sung RY, Leung TF, Wong YO, Li AM, Cheung KL, et al. Randomized, double-blind, placebo-controlled trial of herbal therapy for children with asthma. J Altern Complement Me. 2009;15:1091-7.

53. Lindemann J, David Pampe E, Peterkin JJ, Orozco-Cronin P, Belofsky G, Stull D. Clinical study of the effects on asthma-related QOL and asthma management of a medical food in adult asthma patients. Curr Med Res Opin. 2009;25:2865-75.

54. Watson RR, Zibadi S, Rafatpanah H, Jabbari F, Ghasemi R, Ghafari J, et al. Oral administration of the purple passion fruit peel extract reduces wheeze and cough and improves shortness of breath in adults with asthma. Nutr Res. 2008;28:166-71.

55. Boskabady MH, Javan H, Sajady M, Rakhshandeh $\mathrm{H}$. The possible prophylactic effect of Nigella sativa seed extract in asthmatic patients. Fundam Clin Pharmcol. 2007;21:559-66.

56. Thomas M, Sheran J, Smith N, Fonseca S, Lee AJ. AKL1, a botanical mixture for the treatment of asthma: a randomised, double-blind, placebo-controlled, cross-over study. BMC Pulm Med. 2007;7:4.

57. Chan CK, Kuo ML, Shen JJ, See LC, Chang HH, Huang JL. Ding chuan Tang, a Chinese herb decoction, could improve airway hyperresponsiveness in stabilized asthmatic children: a randomised, double-blind clinical trial. Pediatr Allergy Immunol. 2006;17:316-22.

58. Murali PM, Rajasekaran S, Krishnarajasekar OR, Perumal T, Nalini K, Lakshmisubramanian S, et al. Plant-based formulation for bronchia asthma: a controlled clinical trial to compare its efficacy with oral salbutamol and theophylline. Respiration. 2006;21:457-63.

59. Li S, Wang Y, Shi Y, Yu J, Sun W, Hu H, et al. Regulatory effects of stage-treatment with established Chinese herbal formulas on 
inflammatory mediators in pediatric asthma. J Tradit Chin Med. 2013;33:727-32.

60. Tang B, Shi K, Li X, Wang H, Fang H, Xiong B, et al. Effect of "yang-warming and kidney essence-replenishing" herbal paste on cold-related asthma exacerbation. J Tradit Chin Med. 2013;33:468-72.

61. Miao Q, Wei PC, Fan MR, Zhang YP. Clinical study on treatment of cough variant asthma by Chinese medicine. Chin J Integr Med. 2013;19:539-45.

62. Tahan F, Yaman M. Can the Pelargonium sidoides root extract Eps 7630 prevent asthma attacks during viral infections of the upper respiratory tract in children? Phytomedicine. 2013;20:148-50.

63. Belcaro G, Luzzi R, Cesinaro Di Rocco P, Cesarone MR, Dugall M, Feragalli B, et al. Pycnogenol improvements in asthma management. Panminerva Med. 2011:53:57-64

64. Kalhan R, Smith LJ, Nlend MC, Nair A, Hixon JL, Sporn PH. A mechanism of benefit of soygenistein in asthma: inhibition of eoisinophil p38-dependent leukotriene synthesis. Clin Exp Allergy. 2008;37:103-12.

65. Hoang BX, Shaw DG, Levine S, Hoang C, Pham P. New approach in asthma treatment using excitatory modulator. Phytoher Res. 2007;21:554-7.

66. Liu M, Zhong X, Li Y, Zheng F, Wu R, Sun Y, et al. Xuan Bai Cheng Q formula as an adjuvant treatment of acute exacerbation of chronic obstructive pulmonary disease of the syndrome type phlegm-heat obstructing the lungs: a multicentre, randomized, double-blind, placebocontrolled clinical trial. BMC Complement Altern Med. 2014;14. doi:1472-6882-14-239.

67. Xie Y, Li JS, Yu XQ, Li SY, Zhang NZ, Li ZG, et al. Effectiveness of Bufei Yishen Granule combined with acupoint sticking therapy on quality of life in patients with stable chronic obstructive pulmonary disease. Chin J Integr Med. 2013;19:260-8.

68. Li JS, Li SY, Xie Y, Wang MH, Li ZG, Zhang NZ, et al. Bu-Fei Yi-Shen granule combined with acupoint sticking therapy in patients with stable chronic obstructive pulmonary disease: a randomized, double-blind, double-dummy, active-controlled, 4-center study. J Ethnopharmacol. 2012;141:584-91.

69. Isbaniah F, Wiyono WH, Yunus F, Setiawati A, Totzke U, Verbruggen MA Echinacea purpurea along with zinc, selenium and vitamin C to alleviate exacerbationsof chronic obstructive pulmonary disease: results from a randomized controlled study. J Clin Pharm Ther. 2011;36:568-76.

70. Worth H, Schacher C, Dethlefsen U. Concomitant therapy with Cineole (Eucalyptole) reduced exacerbations in COPD: a placebo-controlled double-blind trial. Respir Res. 2009:10. doi:1465-9921-10-69.

71. Cerda B, Soto C, Albaladejo MD, Martinez P, Sanchez-Gascon F, TomasBarberan F, et al. Pomegranate juice supplementation in chronic obstructive pulmonary disease: a 5-week randomized, double-blind, placebo-controlled trial. Eur J Clin Nutr. 2006;60:245-53.

72. Murali PM, Rajasekaran S, Paramesh P, Krishnarajasekar OR, Vasudevan S, Nalini $\mathrm{K}$, et al. Plant-based formulation in the management of chronic obstructive pulmonary disease: a randomized, double-blind study. Respir Med. 2006;100:39-45.

73. Zhao YL, Song HR, Fei JX, Liang Y, Zhang BH, Liu QP, et al. The effects of Chinese yam-epimedium mixture on respiratory function and quality of life in patients with chronic obstructive pulmonary disease. J Tradit Chin Med. 2012;32:203-7.

74. Li SY, Li JS, Wang MH, Xie Y, Yu XQ, Sun ZK, et al. Effects of comprehensive therapy based on traditional Chinese medicine patterns in stable chronic obstructive pulmonary disease: a four-center, open-label, randomized, controlled study. BMC Complement Altern Med. 2012;12. doi:1472-6882-12-197.

75. Li W, Mao B, Wang G, Chang J, Zhang Y, Wan MH, et al. Effect of Tanreqing Injection on treatment of acute exacerbation of chronic obstructive pulmonary disease with Chinese medicine syndrome of retention of phlegm and heat in Fei. Chin J Integr Med. 2010;16:131-7.

76. Shinozuka N, Tatsumi K, Nakamura A, Terada J, Kuriyama T. The traditional herbal medicine Hochuekitto improves systemic inflammation in patients with chronic obstructive pulmonary disease. J Am Geriatr Soc. 2007:55:313-4.

\section{Submit your manuscript to a SpringerOpen ${ }^{\circ}$ journal and benefit from:}

- Convenient online submission

- Rigorous peer review

- Immediate publication on acceptance

- Open access: articles freely available online

- High visibility within the field

- Retaining the copyright to your article

Submit your next manuscript at $\gg$ springeropen.com 